\title{
Selecting Journal for Publication in the Era of "Haste Predatory Journals and COVID-19"'
}

\author{
Saba Siddiqui ${ }^{1}$, Armin Ahmed ${ }^{2}$, Afzal Azim ${ }^{3}$ \\ Keywords: COVID-19, Open-access platform, Predatory journals. \\ Indian Journal of Critical Care Medicine (2020): 10.5005/jp-journals-10071-23687
}

Dear Editor,

The year of Rat 2020 has brought landmark changes on the planet which is reflected in many spheres of life including the field of biomedical publication.

First, although the open-access platform and paid scientist publication had opened the gates for low quality as well as intentionally dubious scientific journals (also called predatory journals) long ago, the problem has been amplified by the COVID-19 pandemic. During this pandemic, the scientific world requires early and rapid dissemination of information, and such journals can do it very well as they have minimal or absent peer-review process. The term "predatory journals" was coined by Jeffrey Beall, a librarian at the University of Colorado, who also maintained a list of potentially predatory journals called "Beall's list". Identifying predatory journals is often difficult as an objective definition is lacking in the literature. In December 2019, a consensus definition of predatory journals was given in a meeting attended by 43 experts from 10 countries. ${ }^{1}$ The consensus described "predatory publishers/journals" as the ones who are driven by financial gains, spread misleading information, lack transparency, do not follow best editorial/publishing practices, and use aggressive demands. A checklist to identify such journals is much needed and awaited. ${ }^{2}$ The novice needs to remain alert as these journals lure by the rapidity of publication and open-access platform.

Second, Cabell's international, a scholarly analytics company that maintains a list of such journals under the name of "Cabell's blacklist", has withdrawn the potentially racist terminologies from their website, after the death of George Floyd, to show their solidarity in the fight against racism. Their whitelisted and blacklisted journals are now called "journalytics" and "predatory reports", respectively. ${ }^{3}$

Third, even the legitimate journals need to redefine current standards of peer-review and publication as proven by the recent retraction of COVID-19-related papers from high-quality journals, i.e., Lancet and NEJM. ${ }^{4,5}$ Enhancing transparency and legitimacy of scientific literature via "open- peer review process" and "open data" might be the future of high-quality scientific research and publication. The COVID-19 pandemic has allowed us to correct our flaws of living and doing things.

Till the scientific community evolves further, and better publication guidelines and standards are established, we have
${ }^{1}$ Department of Agriculture, Integral Institute of Agricultural Science and Technology (IIAST) Lucknow, Uttar Pradesh, India

${ }^{2}$ Department of Critical Care Medicine, King George Medical University (KGMU), Lucknow, Uttar Pradesh, India

${ }^{3}$ Department of Critical Care Medicine, Sanjay Gandhi Postgraduate Institute of Medical Sciences (SGPGIMS), Lucknow, Uttar Pradesh, India Corresponding Author: Afzal Azim, Department of Critical Care Medicine, Sanjay Gandhi Postgraduate Institute of Medical Sciences (SGPGIMS), Lucknow, Uttar Pradesh, India, Phone: +91 8004904730, e-mail: afzalazim38@gmail.com

How to cite this article: Siddiqui S, Ahmed A, Azim A. Selecting Journal for Publication in the Era of "Haste Predatory Journals and COVID-19". Indian J Crit Care Med 2020;24(12):1284-1285.

Source of support: Nil

Conflict of interest: None

tried to help the young researchers in this era of haste by summarizing the journal submission process in a flowchart (see Flowchart 1).

\section{References}

1. Grudniewicz A, Moher D, Cobey KD, Bryson GL, Cukier S, Allen K, et al. Predatory journals: no definition, no defence. Nature 2019;576(7786):210-212. DOI: 10.1038/d41586-01903759-y.

2. Cukier S, Lalu M, Bryson GL, Cobey KD, Grudniewicz A, Moher D, et al. Defining predatory journals and responding to the threat they pose: a modified Delphi consensus process. BMJ Open 2020;10(2):e035561. DOI: 10.1136/bmjopen-2019-035561.

3. Cabell scholarly analytics https://www2.cabells.com/.

4. Mehra MR, Ruschitzka F, Patel AN. Retraction-hydroxychloroquine or chloroquine with or without a macrolide for treatment of COVID-19: a multinational registry analysis. Lancet. 2020;395(10240):1820. DOI: 10.1016/S0140-6736(20)31324-6.

5. Mehra MR, Desai SS, Kuy S, Henry TD, Patel AN. Retraction: Cardiovascular Disease, Drug Therapy, and Mortality in Covid-19. N Engl J Med. 10.1056/NEJMoa2007621. N Engl J Med. 2020;382(26):2582. DOI: 10.1056/NEJMc2021225.

(-) The Author(s). 2020 Open Access This article is distributed under the terms of the Creative Commons Attribution 4.0 International License (https://creativecommons. org/licenses/by-nc/4.0/), which permits unrestricted use, distribution, and non-commercial reproduction in any medium, provided you give appropriate credit to the original author(s) and the source, provide a link to the Creative Commons license, and indicate if changes were made. The Creative Commons Public Domain Dedication waiver (http://creativecommons.org/publicdomain/zero/1.0/) applies to the data made available in this article, unless otherwise stated. 
Flowchart 1: Flowchart to guide journal selection and submission for publication

- Make a list of Journal from standard sites in the relevant area (e.g.Journal Citation
Reports,https://www.scopus.com/sources.uri,https://www.scimagojr.com/)
- Select journal as per significance (international journals for topics of global interest/regional
journals for topics of region significance)

Check for predatory journals; Discard from your list

Note that it's easier to identify legitimate journal as compared to predatory journal. Discard the ones you are not sure about
Consider following for guidance

- "THINK. CHECK.SUBMIT." initiative*

- DOAJ list and COPE membership of the journal**

- Cabell's international ${ }^{* * *}$

Hints to Identify Predatory journals;

- ABSENT OR MINIMAL PEER REVIEW

- Editorial board lack transparency and expertise in the field

- Insufficient / hides information about the fees

- Quality of published papers is low

- Poorly maintained websites (deadlinks, spelling mistakes)

Check your list of journals for

1) Check need for payment (Does it match with your funding resources?)

2) Check Indexing policy (Does it match with your requirements?)

3) Check frequency of publication (weekly vs. monthly vs. quarterly)

- Make a final tentative list of journals where you can submit your work

- Download a sample article and author guidelines for these journals and read carefully

- Narrative reviews are frequently commissioned, so communicate with the editor before writing a review.

Minor differences in referencing style and word count between journals makes submission process tedious and time-consuming

Points of emphasis in author's guidelines

- Referencing style

- Word count (permissible for title, abstract and main document)

- Subheadings needed for abstract and main document 